\title{
TIME-RESOLVED PHOTOELECTRON SPECTROMETRY OF A DEPHASING PROCESS IN PYRAZINE
}

\author{
L. I. Pavlov ${ }^{1}$, S. I. Pavlova ${ }^{2}$, R. L. Pavlov ${ }^{1}$, Ya. I. Delchev ${ }^{1}$ \\ ${ }^{1}$ Institute for Nuclear Research and Nuclear Energy, Bulgarian Academy of Sciences \\ 72 Tzarigradsko Chaussee Blvd, BG-1784 Sofia, Bulgaria \\ ${ }^{2}$ Departement of Ed. Physics, Faculty of Physics \\ St. Kl. Ohridski University of Sofia, Blvd. J. Bourchier 5, BG-1164 Sofia, Bulgaria
}

(Received October 4, 2001)

\begin{abstract}
The proposed time-resolved spectrometry is of high temporal resolution within the femtosecond scale. Recently, performing of real-time studies of molecular dynamics is of great interest. The photoelectron spectrometry exhibits high sensitivity, since photoionization is an induced process and the electrons can be collected efficiently by an electromagnetic field. Such method is applied to ultrafast dephasing process in molecular pyrazine. The photoelectron imaging allows measurements of speed and angular distributions with unit collection efficiency of electrons. We should note that the photoelectron imaging probes short range and short time dynamics involving the electronic relaxation. The method is characterized by photoionization of NO and further applied to ultrafast dephasing in pyrazine. The combination of time-resolved photoelectron and photoion imaging will allow us to observe photo-induced dynamics of molecules and clusters from time $t=0$ to $\infty$ with a single apparatus. The experimental results are compared with the theoretical analysis of strong impact onto the multi-electron systems.

Key words: molecular dynamics, excited states of molecules, photoelectron spectra, timeresolved methods.
\end{abstract}

PACS number(s): 31.70.Hq, 34.50.Gb, 33.80.Rv

\section{INTRODUCTION}

Time-resolved photoelectron spectometry (PES) is quite promising in probing the photoinduced dynamics of molecules and clusters in gas phase [1-3]. When exciting the system, 2D ion imaging coupled with resonanceenhanced multiphoton ionization (REMPI) proves to be a powerful technique for the measurement of differential cross sections in photodissociation [4], inelastic $[5,6]$ and reactive scattering $[7,8]$ processes. REMPI provides state-selective ionization of products, and imaging of subsequent ions leads to the measurement of stateresolved differential cross-sections. Non-resonant multiphoton ionization with a femtosecond laser pulse is also useful in molecular dynamics experiment since it is versatile in monitoring the population of a variety of species. First of all, an advantage of PES is, that both the singlet and triplet states can be detected, thereby enabling direct observation of intersystem crossing and internal conversion processes. Furthermore, the method exhibits high sensitivity since photoionization is an induced process and electrons can be collected efficiently by an electromagnetic field. Finally, analogously to Raman spectroscopy, the ionization laser can be frequencyfixed while the photoelectron energy is dispersed, which is favourable for applying an ultrafast laser with limited tunability. Photoelectron imaging (PEI), on the other hand, allows routine measurements of speed and angular distributions of photoelectrons with unit collection efficiency of electrons [8]. Although the energy resolution of PEI may be lower than the conventional method, the uncertainty principle limits the energy resolution obtainable in ultrafast spectoscopy, so PEI is quite suited for femtosecond pump-probe experiments. Another feature of PEI to be noted here is that it is applicable to quasicontinuous light sources such as discharge lamps, high repetition-rate lasers, and synchronous radiation.

In this paper, the first femtosecond time-resolved photoelectron imaging (PEI) on two-color photoionization of NO via the $A(3 s \sigma)$ state and ultrafast dephasing in pyrazine are reported. The combination of time-resolved photoelectron and time-resolved photoion imaging allows us to observe photo-induced dynamics of molecules and clusters and these are real-time studies. The method proposed consists of an efficient excitation of molecular system and subsequent decay. Time-resolved PEI probes short range and short time dynamics involving electronic relaxation.

\section{EXPERIMENT}

The molecular beam apparatus consists of a beam source and a main chamber both of which are pumped by magnetically-suspended turbo molecular pumps. A sample gas expanded from a piezoelectric valve in the source is skimmed and introduced into the main chamber as a molecular beam $2 \mathrm{~mm}$ in diameter. The pulse is crossed with pump and probe laser beams in the stacked acceleration electrodes in the main chamber, where the pump pulse excites molecules and a probe pulse further ionizes them. The electrons thus produced are accelerated parallel to the molecular beam and projected onto a positionsensitive imaging detector [9]. The acceleration field provides two-dimensional space focusing, so that only the velocities (or linear momentum) of the electrons perpen- 
dicular to the detector face were observed in the image [9]. The imaging detector consists of a microchannel plate (MCP), a phosphor screen, and a Peltier-cooled chargecoupled device (CCD) camera $(1536 \times 1024$ pixels $)$. The image on the phosphor screen is captured by the camera and integrated for 1800-18000 shots. In order to observe the total photoelectron intensity, the emission from the phosphor screen was monitored with a photomultiplier tube (PMT).

The solid-state laser system consists of an oscillator, amplifier, and nonlinear wavelength tuning devices. The oscillator is a $5 \mathrm{~W}$-diode pumped Ti:sapphire laser $(80 \mathrm{fs}, 82 \mathrm{MHz})$. The output from this oscillator is introduced into a Ti:sapphire regenerative amplifier pumped by $10 \mathrm{~Hz} N d$ : Y AG laser (250 m.J, $532 \mathrm{~nm}$ ). The output from the amplifier (120-150 fs, $10 \mathrm{~mJ} / \mathrm{pulse}, 786 \mathrm{~nm}$ ) is split into two beams. One beam is introduced into a travelling-wave optical parametric amplification system (Topas, Light conversion). Harmonics of the signal or idler waves provided wavelengths down to $300 \mathrm{~nm}$. Shorter wavelength UV light $(210-250 \mathrm{~nm})$ was generated by mixing the output from the optical parametric amplifier with the other half of the fundamental beam in a $\beta-\mathrm{BaB}_{2} \mathrm{O}_{4}(\mathrm{BBO})$ crystal. The tunable UV light and the remaining fundamental light $(<5 \mathrm{~mJ} /$ pulse) emitted coaxially from the crystal were separated by a dichroic mirror to introduce the fundamental light into BBO crystals to produce its harmonics (the second and third harmonics centered at 393 and $262 \mathrm{~nm}$ in the present experiment). The tunable UV light was optically delayed and realigned with the harmonics of the fundamental, and these two beams are irradiated onto the molecular beam. The observed images of electrons were inverted to generate the speed-angular distributions by inverse Abel transform.

\section{RESULTS AND DISCUSSION}

\section{A. $\left[1+1^{\prime}\right]$ REMPI of NO}

Femtosecond time-resolved PEI was tested by observing $\left[1+1^{\prime}\right]$ REMPI of $\mathrm{NO}$ via the $A\left({ }^{2} \sum^{+}\right)$state. A molecular beam of NO $5 \%$ seeded in the He or Ar was crossed with the pump $(225 \mathrm{~nm})$ and probe $(262 \mathrm{~nm})$ light, and the resulting electrons and $\mathrm{NO}^{+}$ions were measured by $1 \mathrm{D}$ and $2 \mathrm{D}$ imaging.

Fig. 1,a shows the time profile of the photoelectron signal. Since the A state of NO has a lifetime of $200 \mathrm{~ns}$ [10] the signal exhibits a flat plateau after a sharp rise determined by the cross-correlation (450 fs) of pump and probe pulses. The photoelectron image observed at a pump-probe time delay of $1 \mathrm{ps}$ is shown in Fig. 1,b. It is seen that the photoelectron angular distribution qualitatively follows a $\cos ^{2} \theta$ distribution with respect to the polarization of the probe laser. We can characterize the angular distribution by

$$
I(\theta) \sim 1+\beta P_{2}(\cos \theta)
$$

with the anisotropy parameter $\beta=2 . P_{2}(x)$ is the second-order Legendre polynomial. However, quantitative analysis of our data yielded $\beta=1.66 \pm 0.01$. This deviation from the atomic model is due to a noncentrosymmetric electron- $\mathrm{NO}^{+}$potential in which the outgoing electron is partially scattered. Previous theoretical and experimental studies on the $\left[1+1^{\prime}\right]$ photoionization of $\mathrm{NO}$ via the $\mathrm{A}$ state $[11,12]$ have shown that the angular distribution of photoelectron in the parallel pump-probe polarization configuration is expressed by

$$
I(\theta) \sim 1+\beta_{20} P_{2}(\cos \theta)+\beta_{40} P_{4}(\cos \theta)
$$

with the dominant contribution of $\beta_{20}=1.6[11,12]$. Our result is consistent with these former works.

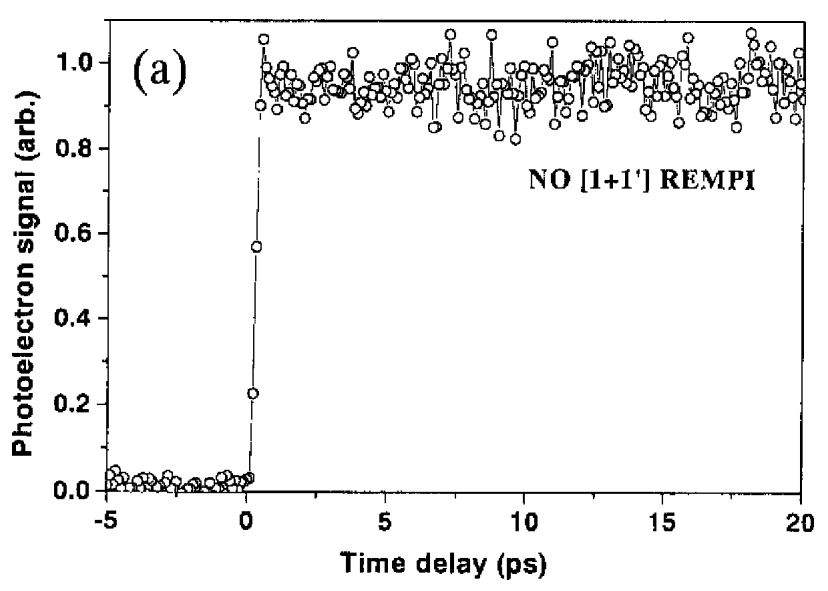

(b) image
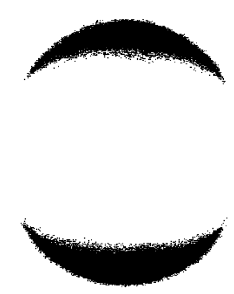

(c) Abel transformed

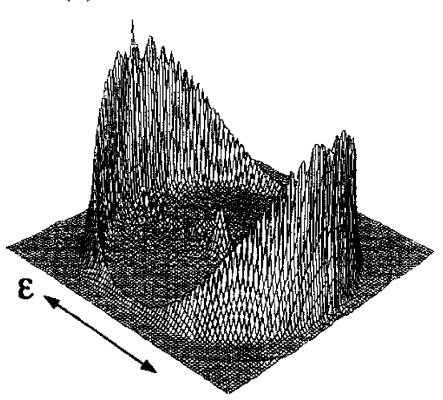

Fig. 1. (a) - time dependence of total photoelectron signal in femtosecond $\left[1+1^{\prime}\right]$ REMPI of NO via $A\left({ }^{2} \sum^{+}\right) v^{\prime}=0$ level, (b) - photoelectron image observed at the pump-probe delay of $1 \mathrm{ps}$, (c) - Inverse Abel transform of the image shown in (b). 
From the width of photoelectron kinetic energy distribution extracted from the inverse Abel transform (Fig. 1,c), the energy resolution in our femtosecond PEI was estimated to be $100 \mathrm{meV}$ at $E=900 \mathrm{meV}$.

\section{B. Intramolecular dephasing in pyrazine}

The broad-band coherent excitation of an intermediate case molecule provides biexponential fluorescence decay where the first component is the dephasing of an optically-prepared singlet state into the population decay of this mixed state $[13,14]$. We have examined this problem by time-resolved photoelectron imaging. Pyrazine in a molecular beam $0.3-3 \%$ seeded in He (a stagnation pressure 1 atm to the vacuum) was excited to the $S_{1}$ vibronic levels by a single photon transition at $320-350 \mathrm{~nm}$ and subsequently ionized by two-photon absorption at $393 \mathrm{~nm}$. The schematic drawing of dephasing process in pyrazine is shown in Fig. 2.

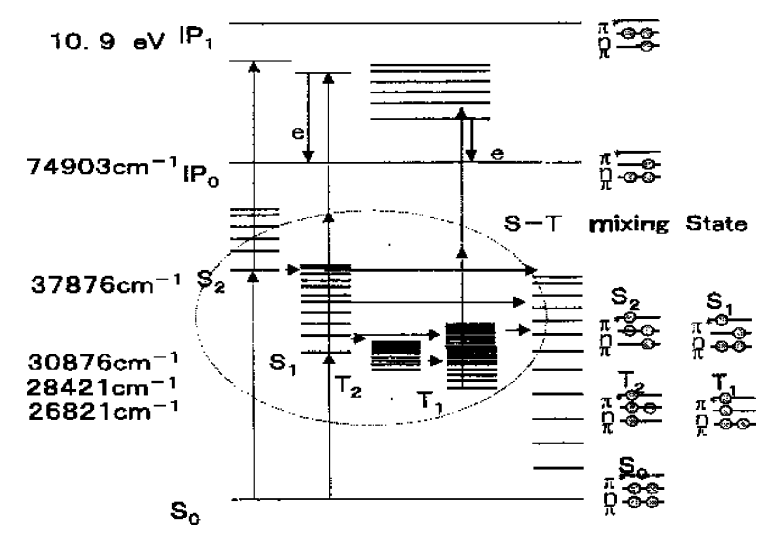

Fig. 2. Schematic drawing of dephasing process in pyrazine.

The power density of our pump laser at the interaction region was less than $10^{10} \mathrm{~W} / \mathrm{cm}^{2}$, while that of the probe laser was about $5 \times 10^{10} \mathrm{~W} / \mathrm{cm}^{2}$. For these power densities, ponderomotive shift of the photoelectron kinetic energies and the alignment of ground-state molecule in the laser field can be neglected. Furthermore, the results obtained were invariant to different partial pressure of pyrazine over the range $0.3-3 \%$ indicating that the effect of cluster formation is negligible. The bandwith of our femtosecond laser does not allow rotational contour, although only a few rotational levels are expected to be populated in a molecular beam.

Fig. 3 shows the observed photoelectron intensity as a function of time delay. As seen in Fig. 3, a, the total electron current (i. e., integral photoionization cross section) shows no time-dependence, which apparently contradicts the fast fluorescence decay data reported previously [14]. Note, however, that photoionization can occur both from the singlet and triplet manifolds. Therefore, Fig. 3, a simply implies that population decay from the mixed singlettriplet state does not occur in this time range. Clearly, the partial photoionization cross section measurement is necessary for examining the dephasing. Thus, the low energy electrons cannot be attributed to the ionization from the singlet to the second cationic state $\left(\pi^{-1}\right)$, but rather must be due to the ionization from the triplet states to the lowest cationic state $\left(n^{-1}\right)$. Ionization from the triplet results in low photoelectron energy, because the triplet states isoenergetic to the singlet have large vibrational energies, and Franck-Condon overlap favours ionization to the highly vibrationally-excited states in cation. Photoelectrons with near zero kinetic energy are concentrated in the centre of the image with a weighting factor that scales with kinetic energy of electrons or the image radius squared. The time-evolution of the singlet and triplet characters were easily measured by masking the phosphor screen and selectively observing the outer and inner part of image with a photomultiplier tube (PMT). When the particular energy region of electrons is monitored in this way, the high energy electron showed a decay with $\tau=104 \pm 3$ ps (Fig. 3,b), while the low energy electron exhibited the corresponding increase with $\tau=97 \pm 8$ ps (Fig. 3,c). As far as we know, this is the first observation of the growth of triplet character due to dephasing from the optically prepared $S_{1}$ pyrazine.

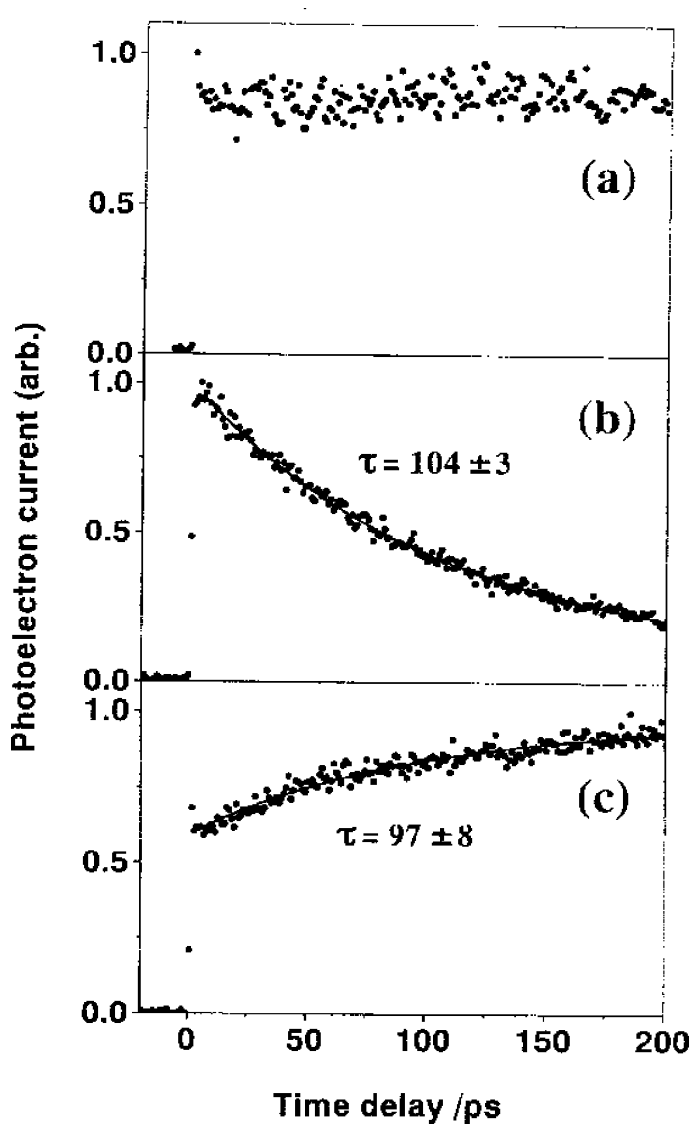

Fig. 3. (a) - time dependence of total photoelectron signal in femtosecond $\left[1+2^{\prime}\right]$ REMPI of pyrazine via the $S_{1}\left[{ }^{1} B_{3 n}\left(n, \pi^{*}\right)\right] 0^{\circ}$ level, (b) - Photoelectron signal for the kinetic energy $E>630 \mathrm{meV}$, (c) - Photoelectron signal for the kinetic energy $E<630 \mathrm{meV}$. 
More detailed dynamics can be learned from the snapshots of electron scattering distributions taken at different time delays shown in Fig. 4. The decay of singlet character and buildup of triplet character can be easily seen in these snapshots. Careful inspection also reveals that the radius of triplet signal shrinks at later time, suggesting relaxation in the triplet manifold.
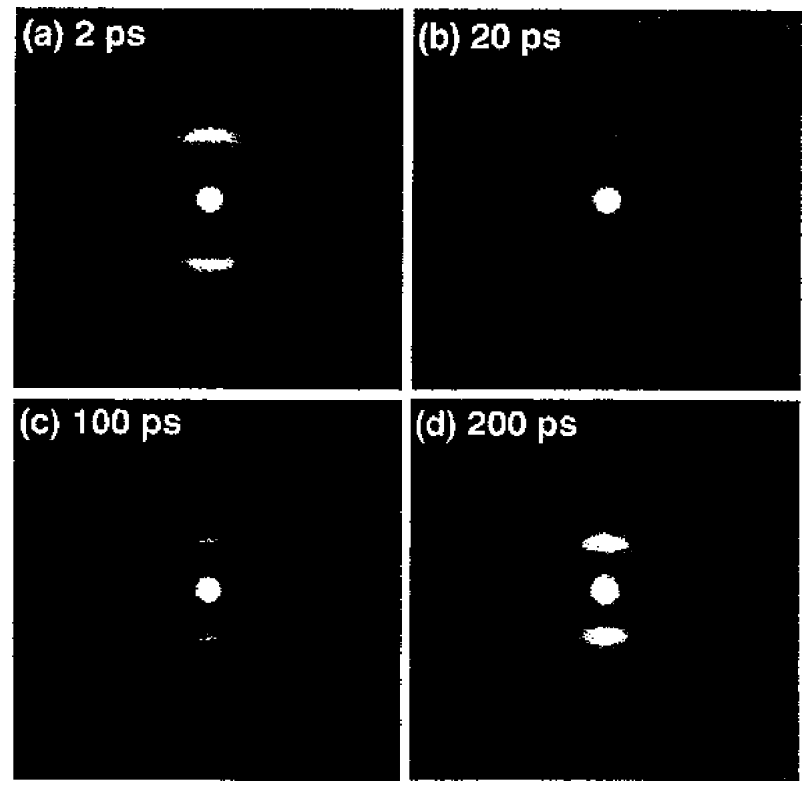

Fig. 4. Inverse Abel transforms $(600 \times 600$ pixels $)$ of photoelectron images of $\left[1+2^{\prime}\right]$ REMPI of pyrazine via the $S_{1}\left[{ }^{1} B_{3 n}\left(n, \pi^{*}\right)\right] 0^{0}$ level at the time delays of (a) $-2 \mathrm{ps}$, (b) $-20 \mathrm{ps},(\mathrm{c})-100 \mathrm{ps},(\mathrm{d})-200 \mathrm{ps}$.

To examine this more quantitatively, photoelectron kinetic energy distributions extracted from the data are presented in Fig. 5. The feature at $200 \mathrm{meV}$ appears instantaneously with the light pulse and decay rapidly. The peak at $200 \mathrm{meV}$ is tentatively assigned to ionization from $T_{2}\left(\pi, \pi^{*}\right)$. The peak observed at $100 \mathrm{meV}$ is assigned to the ionization from $T_{1}\left(\pi, \pi^{*}\right)$. As seen in Fig. 5, two-photon ionization at $393 \mathrm{~nm}$ well covers the FranckCondon region in ionization from $T_{1}$, so that the total ionization signal does not show time-dependence in our experiment.

The angular anisotropy of photoelectron distribution is characterized by $\beta_{2}=0.8$ and 1.0 for the singlet and triplet channels, respectively. The time-dependence of these anisotropy parameters is found to be negligible. We are unfortunately unable to interpret the anisotropy parameter data fully because of two-photon nature of ionization step. It is possible that two-photon ionization involves Rydberg states as the virtual states, and if so, this would determine the angular anisotropy of photoelectron distribution. It is necessary to use $\left[1+1^{\prime}\right]$ ionization scheme and to compare the result with the $\left[1+2^{\prime}\right]$ scheme to examine this possibility.

In our experiment, a static electric field $<700 \mathrm{~V} / \mathrm{cm}$ was used to extract the photoelectrons and project them onto the detector. This field might induce a Stark effect on the molecule. However, previous work has shown that noticeable change of the level structure is only induced by an order of magnitude larger field strength $>10 \mathrm{kV} / \mathrm{cm}$ $[15,16]$. Thus the effect of the extraction field in the short time dynamics of pyrazine can be excluded. It is important, that the dephasing time we obtain is in good agreement even with the previous field-free data [14].

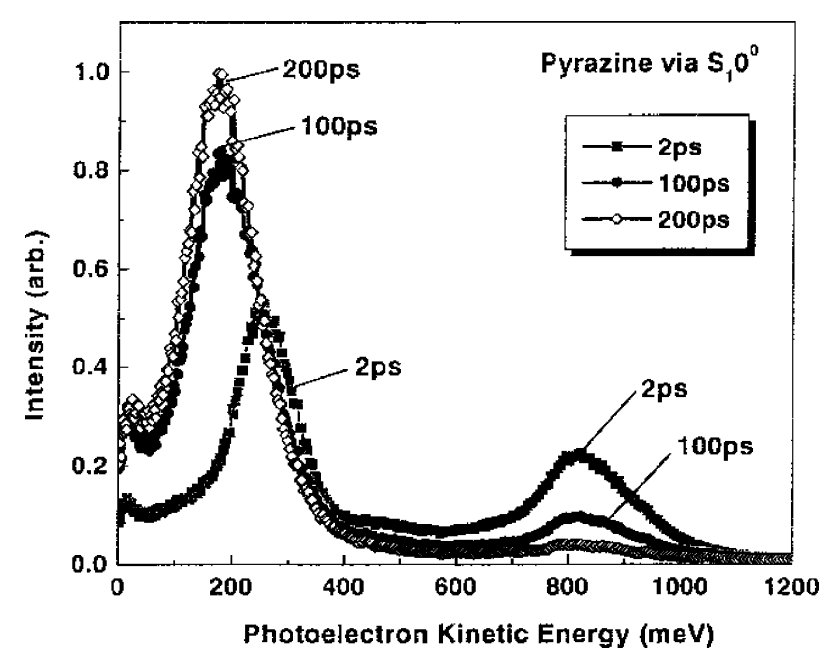

Fig. 5. Photoelectron kinetic energy distribution in femtosecond REMPI of pyrazine via the $S_{1}\left[{ }^{1} B_{3 n}\left(n, \pi^{*}\right)\right] 0^{0}$ level at the time delays of (a) $-2 \mathrm{ps},(\mathrm{b})-20 \mathrm{ps},(\mathrm{c})-100 \mathrm{ps}$, (d) $-200 \mathrm{ps}$.

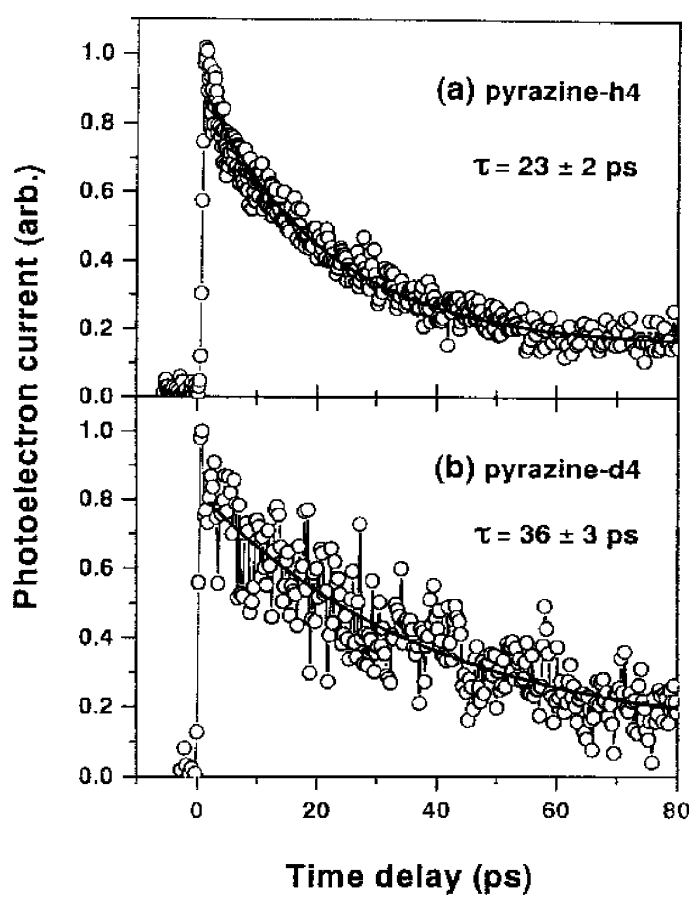

Fig. 6. Time dependence of photoelectron signal in femtosecond $\left[1+1^{\prime}\right]$ REMPI via $S_{2}$ state of $(\mathrm{a})$ - pyrazine-h4 and (b) - pyrazine-d4. 


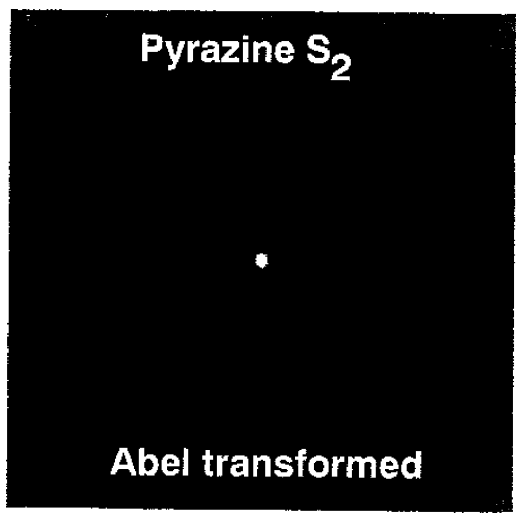

Fig. 7. Inverse Abel transform of the photoelectron images $(600 \times 600$ pixels $)$ observed for $\left[1+1^{\prime}\right]$ REMPI via $S_{2}\left[{ }^{1} B_{2 n}\left(\pi, \pi^{*}\right)\right]$ state at the time delay of $0.6 \mathrm{ps}$.

We should note, that the second excited state of pyrazine $S_{2}\left[{ }^{1} B_{2 n}\left(\pi, \pi^{*}\right)\right]$ is located $7000 \mathrm{~cm}^{-1}$ above $S_{1}\left[{ }^{1} B_{3 n}\left(n, \pi^{*}\right)\right]$ state. The $S_{2}\left(\pi, \pi^{*}\right) \leftarrow S_{0}$ absorption band is broad due to ultrafast $S_{2} \rightarrow S_{1}$ electronic dephasing. We excited pyrazine in a molecular beam, by $262 \mathrm{~nm}$ light to the vicinity of the zero vibrational level in $S_{2}\left(\pi, \pi^{*}\right)$ and subsequently ionized the excited molecules by $220 \mathrm{~nm}$ light.

As shown in Fig. 6, the total photoelectron signal de- cayed with the lifetime of $23 \pm 2 \mathrm{ps}$. Similar measurement on pyrazine-d 4 showed the lifetime of $36 \pm 3 \mathrm{ps}$. The intersystem crossing yield from $S_{1}$ pyrazine is known to sharply fall off near $280 \mathrm{~nm}$ [17], so the observed decay is ascribed to $S_{1} \rightarrow S_{0}$ internal conversion. The longer lifetime observed for pyrazine-d 4 is ascribed to the reduction of Franck-Condon overlap for the accepting modes between $S_{1}$ and $S_{0}$.

As shown in Fig. 7, the anisotropy of photoelectron distribution is rather small, $\beta=0.15 \pm 0.1$, which is contrasted with strong anisotropy observed for $\left[1+2^{\prime}\right]$ REMPI via $S_{1}$ state. This may suggest the role of virtual state for the $\left[1+2^{\prime}\right]$ process.

\section{CONCLUSIONS}

The first femtosecond time-resolved photoelectron imaging (PEI) is presented. The method is characterized by photoionization of $\mathrm{NO}$ and further applied to ultrafast dephasing in pyrazine. Intermediate case behaviour in radiationless transition is clearly observed in time-resolved photoelectron kinetic energy distribution. Femtosecond PEI is with much improved efficiency than conventional photoelectron spectroscopies. It is anticipated that the unifield approach of time-resolved photoelectron and photoion imaging opens the possibility of observing photon-induced dynamics in real time.
[1] V. Blanchetand, A. Stolow, J. Chem. Phys. 108, 4371 (1998).

[2] T. Shultz, I. Fischer, J. Chem. Phys. 109, 5812 (1998).

[3] B. J. Greenblatt, M. T. Zanni, D. M. Neumark, Science 276, 1675 (1997).

[4] A. G. Suits, R. L. Miller, L. S. Bontuyan, P. L. Houston, J. Chem. Soc. Faraday Trans. 89, 1443 (1993).

[5] A. G. Suits, L. S. Bontuyan, P. L. Houston, B. J. Whitaker, J. Chem. Phys. 96, 8618 (1992).

[6] L. S. Bontuyan, A. G. Suits, P. L. Houston, B. J. Whitaker, J. Chem. Phys. 97, 6342 (1993).

[7] M. A. Buntine, D. P. Baldwin, R. N. Zare, D. W. Chandler, J. Chem. Phys. 94, 4672 (1991).

[8] H. Helm, N. Bijerre, M. J. Dyer, D. L. Huestis, M. Saeed, Phys. Rev. Lett. 70, 3221 (1993).

[9] A. T. J. B. Eppink, D. H. Parker, Rev. Sci. Instrum. 68,
3477 (1997).

[10] L. G. Piper, L. M. Cowles, J. Chem. Phys. 85, 2418 (1986).

[11] H. Rudolph, V. McKoy, J. Chem. Phys. 91, 2235 (1989).

[12] S. W. Allendorf, D. L. Leahy, D. C. Jacobs, R. N. Zare, J. Chem. Phys. 91, 2216 (1989).

[13] F. Iamanni, A. Tramer, C. Trie, J. Chem. Phys. 60, 4431 (1974).

[14] P. M. Felker, A. H. Zewail, Chem. Phys. Lett. 128, 721 (1986).

[15] N. Ohta, T. Takemura, Chem. Phys. Lett. 169, 611 (1990).

[16] M. Seel, W. Domcke, J. Chem. Phys. 95, 7106 (1991).

[17] I. Yamazaki, T. Murao, T. Yamaka, K. Yoshihara, Faraday Discuss. Chem. Soc. 75, 395 (1983). 


\title{
ЧАСОВО РОЗДІЛЕНА ФОТОЕЛЕКТРОННА СПЕКТРОМЕТРІЯ ДЕФАЗУЮЧОГО ПРОЩЕСУ В ПИРАЗИНІ
}

\author{
Л. І. Павлов ${ }^{1}$, С. І. Павлова ${ }^{2}$, Р. Л. Павлов ${ }^{1}$, Я. І. Делчев ${ }^{1}$ \\ ${ }^{1}$ Інститут ядерних дослідеень і ядерноӥ енергї \\ Боларсъка академіл наук, бульв. ПІаріарадсъко IIІосе, 72, BG-1784, Софіл, Болааріл \\ ${ }^{2}$ Відділення освітноой фізики, факультет фізики \\ Софійсъкий університет Св. Кл. Оерідсъкого, \\ вул. Й. Боурчер, 5, BG-1164, Софіл, Болгаріл
}

Запропонована часово розділена спектрометрія має високу часову роздільну здатність у межах фемтосекундного масштабу. Віднедавна дослідження молекулярної динаміки в реальному масштабі часу викликає велике зацікавлення. Фотоелектронна спектрометрія має високу чутливість, оскільки фотойонізація $є$ індукованим процесом, і електрони можуть ефективно збиратись електромагнетним полем. Такий метод застосовується до надшвидкого дефазуючого процесу в молекулярному пиразині. Фотоелектронне відображення дозволяє виміряти швидкість і кутові розподіли з одиничним набором ефективности електронів. Зазначимо, що фотоелектронне відображення зондує короткосяжну й короткочасову динаміку, включаючи електронну релаксащію. Метод характеризується фотойонізацією дефазування в пиразині. Комбінація часово розділеного фотоелектронного й фотойонного відображення дозволить нам спостерігати фотоіндуковану динаміку молекул і кластерів на проміжку часу від $t=0$, $\infty$ на одному апараті. Експериментальні результати зіставлено з теоретичним аналізом сильних зіткнень у багатоелектронних системах. 